Afiliada à

Associação Brasileira
de Editores Científicos A B B C

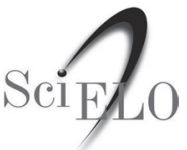

Clarivate
Analytics

scepus

Geoscience

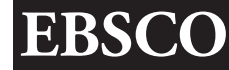

P U B L I S H IN G

Provider of EBSCOhost ${ }^{\circ}$

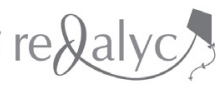

\section{Freedom to publish is the power to be able to choose}

There is something that journal editors face daily and this is the fact that authors are always looking for information about Impact Factor, Qualis, etc., to decide where to publish their articles.

We all know that the impact factor (IF) is a measure of the frequency with which the average article in a journal has been cited in a particular year.

However, it is known that the IF does not have a "correction factor" for the various areas of science, putting them all in the same "bird's nest". Just to exemplify, it is enough to verify that in Brazil, there are about 1240 Law courses (in addition to around 1100 in the rest of the world), and 336 for medicine. However, when one thinks of schools of mining, or of metallurgy, etc., our fingers serve to count them.

The conclusion is simple, some areas naturally produce more articles, more research, more readers, and it is worth asking if the distortions, which certainly exist, have been corrected by the IF, and if these corrections have reached the different areas of knowledge, or even their subareas. The conclusion is simple, although it is known that the number of references cited per article (density of citations) are quite different, the corrections for the different areas do not exist and the IF creators do not perceived this, and if they did, have not created a factor to correct the discrepancies.

Another search by the Brazilian authors is relative to the Qualis of the magazines. In 2006, REM ranked A, even though it was in an area strange to other articles of the journal: Nursing. There was an article about "accidents in construction", whose author was from that area, and perhaps influenced the evaluation committee. Here too, there is a mixture of areas and subareas of engineering, as in the IF, where distortions exist, and once again the "bird's nest" appears.

In the REM files, there is a correspondence received in 1999, in which the evaluation director of the Coordination of Improvement of Higher Education Personnel (CAPES) answered to my questioning about the Qualis subject, stating: the classification in question has the exclusive finality of indicating the repercussion that the product of the scientific and technological research of a given postgraduate program has on the respective area of knowledge. It does not reflect this because it is not related to the objective itself: the scientific merit, the quality or the seriousness of the referenced vehicle (the bold and the underscored text is part of the correspondence). This phrase resembles a television phrase: "Really?".

I recommend reading the article by the editor of CLINICS Magazine, prof. Mauricio Rocha, in 2009: The new Qualis, which has nothing to do with the science of Brazil ... (doi: http://dx.doi.org/10.1590/S1807-59322009000800002). State-of-art.

But, in spite of all these complications, REM has held steadfast during its 83 years, and the title of this editorial, inspired by an announcement, begins with freedom of choice, and ends with the following sentence: exercise your power of choice. I recommend REM, unlike Capes' former evaluation director, and continue in the incessant pursuit of merit, quality and seriousness; goals of all who make up the REM team.

\footnotetext{
Prof. Jório Coelho ${ }^{1}$

https://orcid.org/0000-0001-5041-5085

'Editor Chefe

Universidade Federal de Ouro Preto - UFOP, Escola de Minas, Departamento de Geologia

Ouro Preto - Minas Gerais - Brasil

E-mail: editor@rem.com.br
} 